\title{
Utilizing a Multi-Step Consensus-Building Process to Create a Shared Departmental Definition of Community Engagement
}

\author{
Kerry K. Fierke, EdD; Laura C. Palombi, PharmD, MPH, MAT \\ Department of Pharmacy Practice and Pharmaceutical Sciences, University of Minnesota College of Pharmacy, Duluth
}

\begin{abstract}
A multidisciplinary department at a College of Pharmacy utilized a multi-step consensus-building process to create a shared departmental definition of community engagement that was consistent with the department's mission and vision. Throughout the consensus building and engaged department process, faculty and staff were given opportunities to participate in community-engaged work and departmental activities, including updates in regular scheduled department meetings. This allowed faculty to have a reference and common understanding of the concept of community engagement when striving towards outlined promotion objectives. A shared understanding of what constitutes community engagement was necessary to ensure that all members of the interdisciplinary department are working toward a common goal and shared vision.
\end{abstract}

Keywords: Community, Engagement, Consensus-building, Engaged Department

\section{Introduction}

Even though universities and their surrounding communities have enjoyed mutually beneficial and fruitful relationships for hundreds of years, the academic community engagement movement of the 1980's facilitated an increased interest in community engagement and a renewed commitment to the role of community involvement. ${ }^{1}$ Community engagement has since been recognized for providing value to faculty service, research, and teaching ${ }^{1,2}$ as well as student learning. ${ }^{3,4}$ Despite the recognized value of community engagement in academia, barriers to implementing sustainable and fruitful community partnerships continue to challenge the academic community. ${ }^{5,6,7}$ One identified barrier to incorporating community engagement into an academic department is the lack of common definition of what constitutes community engagement. ${ }^{5}$ A particular department's lack of shared vision for community engagement was determined to be a significant barrier to the implementation of sustainable and fruitful partnerships.

In order to create a common definition of community engagement, a shared visioning practice was conducted with one interdisciplinary pharmacy department. This type of collaborative process in creating a shared vision is known to be beneficial in maximizing involvement of all parties involved and ensuring that the vision is put into action. ${ }^{8,9} \mathrm{~A}$ shared vision was needed to establish a common understanding of community engagement, and then to define what community engagement means to a department. This paper describes the

Corresponding author: Kerry K. Fierke, EdD

University of Minnesota College of Pharmacy

Dept of Pharmacy Practice and Pharmaceutical Sciences

232 Life Science, 1110 Kirby Drive, Duluth, MN 55812-3003

Phone: 218-726-6027; Email: kkfierke@d.umn.edu collaborative process that was used to engage all faculty and staff in a multidisciplinary academic pharmacy department that ultimately led to the creation of a new departmental definition of community engagement.

\section{Background}

Academic pharmacy has not consistently realized the benefits of community engagement, and incorporation of engagement into academic pharmacy careers has not been without its challenges. ${ }^{5}$ It must be recognized, for example, that building trusting relationships with the community takes time and a willingness to "let go" of some details to share ownership of projects with the community. ${ }^{5}$ It is beneficial when the institution recognizes engagement as an approach to research, practice, and service and not just a stand-alone activity. ${ }^{5}$

In an effort to increase community engagement in academic pharmacy careers, the 2004-05 American Association of Colleges of Pharmacy (AACP) Argus Commission Report addressed the call for greater civic responsibility on the part of institutions of higher education. This Commission also examined opportunities to expand research and scholarship that focused on improving community health. ${ }^{10}$ Later, in 2014, AACP's Research and Graduate Affairs Committee (RGAC) assessed the landscape of academic pharmacy's current work in the area of community-engaged scholarship, identifying barriers and opportunities for those involved in communityengaged research, defining community-engaged scholarship metrics, and identifying and promoting funding opportunities for academic pharmacy in community-engaged scholarship. ${ }^{11,12}$

The RGAC adopted a definition of community-engaged scholarship as "teaching, discovery, integration, application and engagement that involves the faculty member in a mutually beneficial partnership with the community and has the following characteristics: clear goals, adequate preparation, appropriate methods, significant results, effective 
presentation, reflective critique, rigor and peer-review." ${ }^{13}$ The RGAC also noted a gap between academic pharmacy's goals in community-engaged scholarship and the slow pace of acceptance of this type of work in academic pharmacy. Recognizing this gap, RGAC developed a vision statement to guide academic pharmacy: "The academy has the responsibility to improve health at the community's interface with the practice of pharmacy through scholarship." ${ }^{13}$

The concept of community engagement is supported not only by the mission and vision statements of many universities, colleges of pharmacy, and collegiate departments, but also by the profession of pharmacy. Most versions of the "Oath of a Pharmacist" - which outlines the principles of behavior that guide the profession - promise a lifetime of service to others through the profession of pharmacy, considering the welfare of humanity and relief of suffering as primary concerns. ${ }^{12}$ Despite the known value of community engagement, many academic departments may not have a shared vision or definition regarding community engagement; this lack of a shared vision and a shared definition may serve as a barrier to sustainable community engagement. $^{5}$ A shared visioning process may therefore serve as a useful tool for academic departments that seek to fully embrace community-engaged research, scholarship, practice, and service.

This collaborative engagement process is consistent with the leadership approach of Kouzes and Posner, ${ }^{13,14}$ who describe leadership as an opportunity to mobilize for a common "shared aspiration." Because a shared visioning process would ideally inspire those who are engaged in the process, all departmental faculty and staff - those who would be living the vision in their respective communities - were included. Also included was a key community member and research partner who had participated in the Engaged Department initiative; this community member offered input and guidance throughout the process.

Recognizing the benefits of purposefully pursuing a leadership approach to consensus-building in a multidisciplinary department, the department Pharmacy Practice and Pharmaceutical Sciences (PPPS) chose to use a shared visioning approach to engage all faculty and staff in reaching consensus on a definition of community engagement. The department
PPPS sought to reach a definition consistent with their mission, vision, and strategic plan.

\section{Methods}

The process of creating a definition for "community engagement" involved faculty and staff within a college of pharmacy in a multi-step initiative occurring over a six-month period. This definition was intended to be customized to meet the needs of the department and the work within the various partner communities. The approach incorporated departmental faculty meetings, college-wide assemblies, and departmental and collegiate strategic planning retreats to broadly discuss and actively work on creating a shared definition of community engagement.

The first step began with a lead faculty orchestrating a team involved in a $\$ 7500$ grant from the University of Minnesota Office of Public Engagement; this grant focused on community engagement on a topic of each departments' choosing. The leadership team included five core faculty, one core community member from a local rural public health department striving to more effectively address the opioid crisis, and two consultative faculty, who participated in multiple university-wide, full day engagement learning and coaching sessions led by the Office of Public Engagement. The community member who participated in the Engaged Department initiative led community advisory councils and an opioid-focused coalition in her county and was able to provide the Engaged Department team with critical feedback on initiatives.

The Office of Public Engagement grant funding included the previously described team working on continually assessing the progress toward community engagement. ${ }^{15} \mathrm{~A}$ critical component of that work includes revisiting annually the five critical dimensions of community engagement. ${ }^{15}$ Therefore, it was decided early within the engaged department process, initiated in January 2016, that coming to consensus on a definition of community engagement was the most critical component of the departments' engaged work in the community. In August of 2016, approximately six months after the engaged department grant kick off, the department PPPS convened a retreat that focused on departmental engagement and coming to consensus on a definition of community engagement. The entire process lasted one year (Figure 1).

Figure 1. Definition timetable

\begin{tabular}{|c|c|c|c|}
\hline August 2016 & November 2016 & December 2016 & August 2017 \\
\hline $\begin{array}{c}\text { Shared Vision Retreat where faculty } \\
\text { shared common language to identify } \\
\text { themes and develop preliminary } \\
\text { descriptions of community } \\
\text { engagement }\end{array}$ & $\begin{array}{l}\text { Using descriptive reports } \\
\text { from the Shared Visioning } \\
\text { Retreat, lead faculty } \\
\text { created definition } \\
\text { through consensus }\end{array}$ & $\begin{array}{l}\text { Unanimous faculty vote } \\
\text { on definition created by } \\
\text { lead faculty using } \\
\text { descriptive reports }\end{array}$ & $\begin{array}{c}\text { Survey to faculty and staff } \\
\text { regarding community } \\
\text { engagement }\end{array}$ \\
\hline
\end{tabular}


Once the core and consultative faculty had a defined objective and process, the remaining faculty and staff were engaged in the consensus-building process. This included an overview of the process and regular department meetings with engagement status updates. During a department retreat in August 2016, all faculty and staff in attendance were involved in a shared visioning process to gather feedback on ways that engaged community activities exist within the department. During this process faculty and staff were asked three questions, based on the model by Senge ${ }^{8,9}:$ 1) How is the university currently engaging with communities? 2) Where do we want to go next? 3) How do we get there? Participants were asked to discuss these questions one at a time. Participants responded to the first question by individually writing ideas on multiple post-it notes. In small groups, they were then asked to place each individual idea on their group's poster board. The small groups then identified and labeled ideas, grouping them into overarching themes. The process continued with each of the three questions. Groups were then asked to create preliminary descriptions of community engagement based on the themes that came from their group. These preliminary descriptions were then collected by the authors.

After the retreat, a follow-up meeting was scheduled with the core and consultative group of faculty, including a community member who was a part of the Engaged Department process. The small group evaluated preliminary descriptions of community engagement from the retreat. A departmental definition of community engagement - in which descriptions, ideas and concepts from the faculty and staff - was created at this meeting. This definition was presented the following month at the December 2016 department meeting, where a vote on the departmental definition of community engagement unanimously passed. Upon completion of the definition, faculty and staff were surveyed regarding their input of the process and involvement and understanding of the definition. This data provided an opportunity to measure the knowledge and skills of faculty and staff to incorporate community engagement in the quad-partite mission of research, practice, teaching and service. ${ }^{15}$

\section{Results}

The process described allowed for the participation of all 38 faculty and staff in a multi-step consensus-building process that resulted in a final definition of community engagement (Figure 2). This definition was unanimously approved during a final departmental meeting vote and can be seen in Figure 2, Departmental Definition of Community Engagement.

Figure 2. Departmental Definition of Community Engagement

"In the department PPPS, community engagement is a partnership matching community and departmental knowledge, skills, interests and resources to improve health; the goals of this partnership include shared decision making in creating healthy communities and sustained public commitment."

\section{Discussion}

Coming to consensus on a departmental definition of community engagement was determined by the engaged faculty team to be a first and necessary step to initiation of engaged department programming. A shared understanding of what constitutes community engagement was necessary to ensure that all members of the interdisciplinary department are working toward a common goal and shared vision. The Engaged Department Initiative allowed the PPPS department to inform the collegiate strategic plan 2017-2022 by specifically identifying outcomes of community engagement that could serve as strategic plan priorities.

The strategic plan recognizes that continuation of the engaged work of the department "exemplifies pharmacists answering a call for a public health crisis where pharmacists are lending expertise and leadership in developing strategic partnerships with those with similar goals for addressing a critical issue."16 The definition was critical as the term community engagement continues to be included in the College strategic plan and 7.12 promotion documents where a definition was previously lacking. This allows faculty to have a reference and common understanding of the concept of community engagement when striving towards outlined promotion objectives.

In addition to ensuring that all faculty understood how the department defined community engagement, an understanding of current community engaged activities in the department was gained through the consensus-building process. Faculty members were surprised by how little they knew about the community-engaged activities that their colleagues were immersed in; discussions focused specifically on community engagement allowed faculty to gain an appreciation for the diversity, breadth and scope of engagement represented in the department. These discussions which took place informally and during scheduled department meetings sparked dialogue focused on new and innovative ways that less engaged faculty members might be able to work more effectively in their communities, and how mentoring on engagement might be facilitated within the department. The consensus-building process allowed for faculty and staff to articulate the importance of engagement in the department 
and to describe current initiatives with an "elevator speech." Being prepared to give such a speech allows faculty and staff to quickly and comfortably share the department's initiatives with community members and non-departmental faculty and staff members.

Throughout the consensus building and engaged department process, faculty and staff were given opportunities to participate in community-engaged work and departmental activities, including updates in regular scheduled department meetings. Faculty who were heavily engaged in the community felt comfortable inviting other interested department members to community-engaged events and activities. Mentoring of newer faculty who were interested in community-engaged work became more purposeful and powerful. Although not all faculty and staff participated in all activities, the department as a whole reported feeling included in these activities. Although there is a current understanding of the definition, it is important to note that the work on incorporating community engagement is ongoing. It will continually need to be brought to the forefront with faculty in various venues including departmental, strategic planning, and research meetings.

\section{Limitations}

The creation of a common definition of community engagement for faculty and staff took place during departmental meetings and retreats. Due to the logistical structure required for gathering information, students were not involved in the overall consensus-building process. While students are included in community engagement research and community forums, no specific data were gathered to include their involvement overall, however the "culture of engagement" permeates student life deeply, as has been the case for years before the described initiative. Further research will include the impact of connecting community engagement with student learning and outcomes.

\section{Conclusion}

This process allowed one department to bring together a definition along with a higher level of attention to community engagement to the entire College of Pharmacy. This provided opportunity during a college-wide strategic planning session to incorporate goals and initiatives related to community engagement in the 2017-2020 collegiate strategic plan. The focused attention on the department's current work in community engagement, the visioning process, and the creation of the final definition of community engagement brought increased attention to the role that community engagement can play in the quad-partite mission of Research, Practice, Teaching and Service.
Because of the consensus building process, relationships between community partners and faculty members have become deeper and more purposeful. The common definition of community engagement has been implemented by the majority of faculty during their interactions with community partners and with students, and they've been better able to describe the research of other faculty in the department as well. ${ }^{15}$ This process has resulted in greater recognition of a longstanding tradition of community engagement within a department, as well as a strengthening of relationships between this department and the larger campus community. The process and definition have also allowed for current relationships to be developed further.

The process of gaining knowledge of and creating a shared definition of engaged community has provided a structure for faculty to reference as a part of their teaching, practice and scholarship. It has also provided awareness for faculty to evaluate current and potential research initiatives and to identify additional strategic engagement opportunities with local communities. Incorporating a consensus-building process for the creation of a definition allowed for the faculty and staff to engaged in the process and own the department definition. The final definition is in use today and is referenced as a foundation in discussions about how members of the department can identify initiatives that support community strategy and the Departmental Mission.

Acknowledgements: The authors gratefully acknowledge the dedication and support of the faculty and staff of the Pharmacy Practice and Pharmaceutical Sciences Department, including the members of the community engagement leadership team: Grant Anderson, Tim Stratton, Paul Ranelli, Karen Bastianelli, and Mark Schneiderhan.

The authors acknowledge the University of Minnesota Office of Public Engagement that provided a grant focused on community engagement.

The authors acknowledge the statistical analysis assistance of Scott Lumos.

The authors declare no conflicts of interest. This work has not been published or presented elsewhere. IRB exemption granted. 


\section{References}

${ }^{1}$ Sorensen TD, Davis RL, Balidemaj F, et al. Sharing Community Engagement in Pharmacy - An Invitation. Inov Pharm. 2011;2(1): Article 24.

${ }^{2}$ Community-Campus Partnerships for Health. https://www.ccphealth.org Accessed on January 5, 2018.

${ }^{3}$ Seifer SD. Service-learning: Community-campus partnership for health professions education. Acad Med.1998;73(3):273-277.

${ }^{4}$ Roche VF, Jones RM, Hinman CE, Seoldo N. A Service-Learning Elective in Native American Culture, Health and Professional Practice. Am J Pharm Ed. 2007;71(6): Article 129.

${ }^{5}$ Palombi LC. Facilitating Community Engagement in Academic Pharmacy Careers. Inov Pharm. 2017;8(3): Article 6.

${ }^{6}$ O'Meara KA, Jaeger AJ. Preparing Future Faculty for Community Engagement: Barriers, Facilitators, Models, and Recommendations. J Higher Ed Outreach and Engagement. 2006;11(4):3-26.

${ }^{7}$ Driscoll A. Carnegie's Community-Engagement Classification: Intentions and Insights. Change: The Magazine of Higher Learning. 2008;40(1):38-41.

${ }^{8}$ Senge PM. The Fifth Discipline: The Art and Practice of the Learning Organization. New York: Currency, Doubleday; 1990.

${ }^{9}$ Senge PM, et al. The Fifth Discipline Fieldbook: Strategies and Tools for Building a Learning Organization. New York: Currency, Doubleday; 1994.

${ }^{10}$ Smith RE, Kerr RA, Nahata MN, et al. Engaging Communities: Academic pharmacy addressing unmet public health needs. Report of the 2004-05 Argus commission. Amer J Pharm Ed. 2005; 69: Article S22.

${ }^{11}$ Bloodworth LS, Haines SL, Kearney KR, et al. Considerations for embracing and expanding community engaged scholarship in academic pharmacy: Report of the 2013-2014 Research and Graduate Affairs Committee. Am J Pharm Ed. 2014 ; $78(8)$ : S8.

${ }^{12}$ American Pharmacists Association, Oath of a Pharmacist. http://www.pharmacist.com/oath-pharmacist. Accessed on December $12,2016$.

${ }^{13}$ Kouzes JM, Posner BZ. The Leadership Challenge: How to Keep Getting Extraordinary Things Done in Organizations. San Francisco, CA: Jossey-Bass Publishers; 1995.

${ }^{14}$ Kouzes JM, Posner BZ. The Student Leadership Challenge. San Francisco, CA: John Wiley \& Sons, Inc.; 2008.

${ }^{15}$ Palombi LC, LaRue AF, Fierke KK. Facilitating Community Partnerships to Reduce Opioid Overdose: An Engaged Department Initiative. Social and Administrative Pharmacy, doi.10.1016; 2018.

${ }^{16}$ University of Minnesota - College of Pharmacy Strategic Plan 2017-2022.

https://www.pharmacy.umn.edu/sites/pharmacy.umn.edu/files/umcop_strategicplan_5.pdf Accessed on January 5, 2018. 